\title{
The Selection of Fast Patrol Boat (FPB) Propeller Ship to Optimize Machine Usage of MTU 16V 595 TE 701 Using Harvald Guldhamer Method and Engine Propeller Matching (EPM)
}

\author{
Arica Dwi Susanto*, I. Nengah Putra. A, Sentot Patria. W.S, Oyu Mulia. S and M. Agus Arif \\ Indonesian Naval Technology College, STTAL., Bumimoro-Morokrembangan, Surabaya 60187, Indonesia
}

Received 9 November 2017; Accepted 18 February 2019

\begin{abstract}
To actualize a large, strong and professional Navy force, the Fast Patrol Boat ship repowering Diesel engine without replacing the ship propeller was done. Harvald Guldhamer Method and Engine Propeller Matching methods were used to obtain optimum results on the propulsion system and determine ship resistance. The analysis refers to machine diagram performance of MTU 16V 595 TE 70L The calculation result was used as an alternative comparison to Wageningen propeller series type B $4-85$ at $91.975 \%$ propeller load with speed of 25 knot. It was still in a work area propeller engine which was outside of work machine area of $89,650 \%$. Based on the fact that the propeller wageningen series type B 4-70 was still in the propeller engine working area of $94.909 \%$ propeller load, it can be concluded that there was a suitability between the power characteristics of the machine with propeller power.
\end{abstract}

Keywords: Ship Resistance, Power Boats, Propeller, Ship Propulsion, Engine propeller matching.

\section{Introduction}

Fast Patrol Boat (FPB) is a type of ship that have combat capability, limited great strike power and ideal avoidance speed to hide among the islands [1].

This paper have any literature to support the research about it, for example paper with title An Approximate Method For Calculation of Mean Statistical Value of Ship Service Speed on a Given Shipping Line, Useful in Preliminary Design Stage [2]. Experimental Investigation on Stern-Boat Deployment System and Operability For Korean Coast Guard Ship [3]. Performance of VLCC Ship with Podded Propulsion System and Rudder [4]. Introduction to Naval Architecture [5]. Basic Ship Theory [6]. Practical Ship Design [7]. Ship Resistance and Propulsion : Practical Estimation of Ship Propulsive Power [8]. Practical Ship Hydrodynamics [9]. Effect of Fluid Density on Ship Hull Resistance and Powering [10]. Ship Design and Contruction [11]. Resistance Propulsion and Steering of Ship [12]. Predictive Analysis of Bare-Hull Resistance of a 25,000 Dwt Tanker Vessel [13]. Resistance and Propulsion of Ships [14]. Hydrodynamic of Ship Propellers [15]. Ship Design for Efficiency and Economy [16]. Design of Propulsion Systems for High-Speed Craft [17]. Amethod of Calculation of Ship Resistance on Calm Water Useful at Preliminary Stages of Ship Design [18]. Increase of Ship Fuel Consumption Due to the Added Resistance in Waves [19]. An Inventigation Into The Resistance Components of Converting a Traditional Monohull Fishing Vessel Into Catamaran Form [20]. Simulation of a Free Surface Flow over a Container Vessel Using CFD [21]. Empirical Prediction of Resistance of

*E-mail address: aricadsusanto@gmail.com ISSN: $1791-2377$ @ 2019 School of Science, IHU. All rights reserved. doi:10.25103/iestr.124.25
Fishing Vessels [22]. Designing Constraints in Evaluation of Ship Propulsion Power [23]. Coefficients of Propeller-hull Interaction in Propulsion System of Inland Waterway Vessels with Stern Tunnels [24]. Cost optimization of marine fuels consumption as important factor of control ship's sulfur and nitrogen oxides emissions [25]. Numerical Investigation of the Influence of Water Depth on Ship Resistance [26]. The Wageningen Propeller Series [27]. Principles of Naval Architecture Second Revision [28]. Marine Propulsion [29].

The current condition did not meet the combat capability as expected in terms of weaponry and machinery. There was speed reduction, the original cruising speed was 25 knots, and the actual speed was only 20 knots only. Thus, it was necessary to analyze the vessel by using propeller matching engine process, in which the process of propeller matching engine was expected to have compatibility between power engine characteristics with propeller power [30].

This Paper is organized as follows. Section 2 review about the basic ship theory. Section 3 gives result and 4 discussion of research. Finally, in section 5 present conclusion of this paper.

\section{Research Methodology}

\subsection{Technical Concept}

In the selection of propellers according to the characteristics of the ship's propulsion engine, it is expected to have great combat capability and have such conditions:

1. High Accuracy, It allows the tactical and technical information to deliver quickly so that decisions can be obtained accurately and rapidly.

2. High Acquacition, This ensures control over the threat better, it requires the sewaco system and platform to be reliable.

3. High Speed, With the speed and agility of the vessel, 
it allows to conduct capability.

\subsection{Propulsion System of The Ship}

The ship propulsion system, which is the exact matching between prime mover (diesel engine, gas turbine, steam turbine) and propeller from ship [31]. Matching completion is not only seen from the engine or propeller point of view, but both are an integrated problem. In FIG. 1 there is provided a definition of the variables in terms of power, torque, and velocity

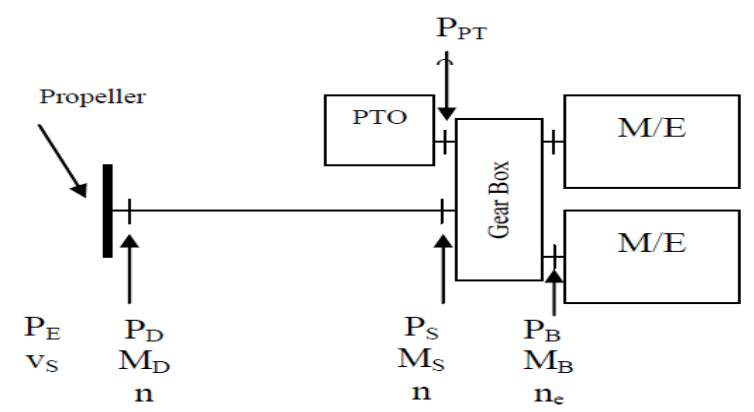

Fig. 1. Variable related with Matching Problems

\subsection{Ship Resistance}

The ship's resistance $(\mathrm{R})$ at a certain velocity is the fluid force acting opposite the movement of the vessel. The resistance will be the same as the fluid force component working parallel to the axis of the ship's movement.

The required power (effective power) to drive the ship in water or to draw the vessel at speed Vs is:

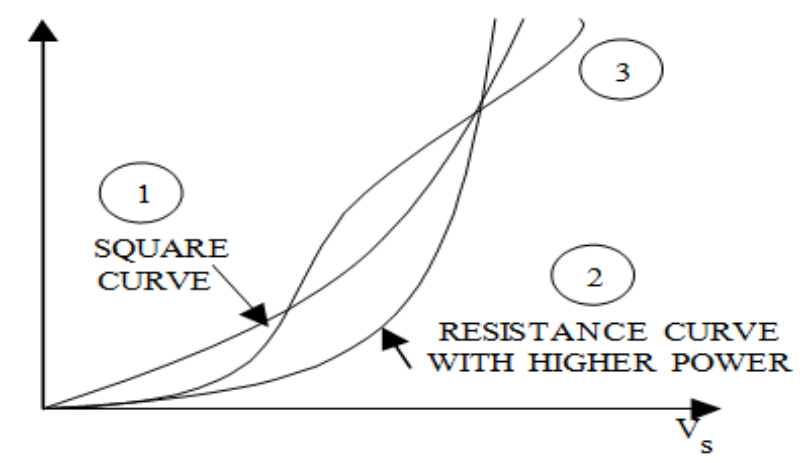

Fig. 2. Resistance-Speed Curve

Notes: (1) Quadratic relationship of

Fn $=0,1-0,2$, (2) High speed ship,

(3) Type, planning craft, swath ship

This is true only for relatively low velocity ships with froude number of $(F n=0,1-0,2)$ and depends on the hull shape [32]. For high speed vessels, ship resistance is no longer a quadratic relationship of speed or with the rank of more than two.

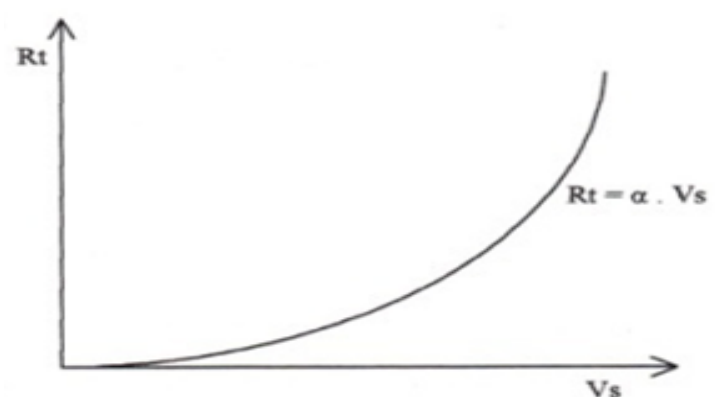

Fig. 3. The Relationship Between Total Resistance and Speed of The
Ship

\subsection{Displacement}

Displacement is the weight of liquid displaced by the hull under the water surface. When the vessel floats in the balance state/motionless then the downward pressure equal to the pressure of the liquid to the hull. Thus the overall weight of the vessel and its contents at that time equal to the weight of liquid displaced by the hull immersed in a liquid in which the vessel is located [8].

Displacement : Lwl x B x T x CB x density of sea water (ton)

\subsection{Volume Displacement}

The volume of liquid displaced by the hull under the surfacewater where the ship is located [8].

Volume displacement: LWL x B x T x CB

\subsection{Selection of The Main Engine}

In the selection of the main engine, it is necessary to calculate the need of power engine. There are several indicators that need to be sought in order toobtain the desired results, those are effective horse power (EHP), thrust horse power (THP), delivery horse power (DHP), shaft horse power (SHP) dan brake horse power (BHP) [8]:

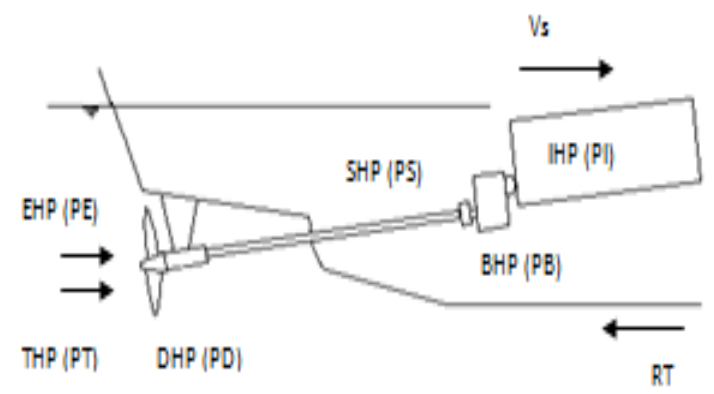

Fig. 4. Ship propulsion system

\subsection{Propeller}

In propeller selection, there are some characteristics that must be considered and will be the main consideration, namely: propeller type, propeller diameter, pitch ratio and the number of propeller propeller blade.

The propeller type selection with the most optimal level of efficiency, can be found using the Bp- $\delta$ diagram.

The steps in propeller selection is as follows:

$$
\text { a. Bp Calculation }
$$

$B p=\frac{N p \times \sqrt{P_{d}}}{V a^{5 / 2}}$

b. Cut off the Bp with optimum line propeller of efficiency.

c. $\quad(\mathrm{P} / \mathrm{D}) \mathrm{o}$ and $\delta$ o value interpretation

d. Do value determination

$D o=\frac{\delta o \times V a}{N p}$

e. Determination of $\mathrm{Db}$ value (behind the hull. For ship using

Single Screw $D_{B}=0,95$. Do and Double Screw $\mathrm{D}_{\mathrm{B}}=0,97$. Do 


$$
\begin{gathered}
\mathrm{f} . \\
\delta_{B}=\frac{D_{B} \times N p}{V a}
\end{gathered}
$$$$
\delta_{\mathrm{B}} \text { Calculation }
$$

g. Cut off the initial Bp with $\delta_{\mathrm{B}}$. This condition was already in behind the hull.
h.
$(\mathrm{P} / \mathrm{D})_{\mathrm{B}}$ and Efficiency Interpretation

\subsection{Engine Propeller Matching}

The matching process between the propulsion engine and the propeller is an essential process for obtaining optimal conversion between fuel and thrust under operating conditions which ensures the working safety of the propulsion and propeller motors. Matching process is not only done from the side of the motor only or from the side of the propeller, but must be handled as a whole. The matching process is basically based on power characteristics vs rpm or torque vs rpm of diesel engines and propellers. Similarly, the torque generated by the driving force multiplied by the ratio of the reduction gear, and it shall be proportional to the propeller torque of the same rotation. Since the characteristics are shown in graphical form, in the application matching is finding intersection (data domain point, torque and rpm are the same) of the curve.
Then the parameters of the motor and propeller are adjusted so that the desired intersection can be obtained. The propeller matching engine process becomes complex with changes in its service conditions. They are the changes in ship resistance due to fouling of ships, weather and ship-laden changes.

\subsection{Method of Research}

Fast Patrol Boat (FPB) and MTU 16V 595 TE 70L engine resistance analysis to propeller with supporting theory.

Propeller analysis would be selected against optimum installed engine power. The method used in this research is literature study, field study, maxsurf program calculation, engine propeller matching and numerical calculation [33]

\section{Result and Discussion}

\subsection{Calculation of Ship Resistance}

In the calculation of ship resistance, beside using formulas that exist in the resistance ship book with the help of excel program on the computer, maxsurf program was also used for comparison so that the accurate results could be obtained.

\subsection{Propeller Selection}

The calculation results to find the efficiency of Wageningen serieswas performed using the data presented below:

Table 1. Propeller Wageningen Series Calculation Results

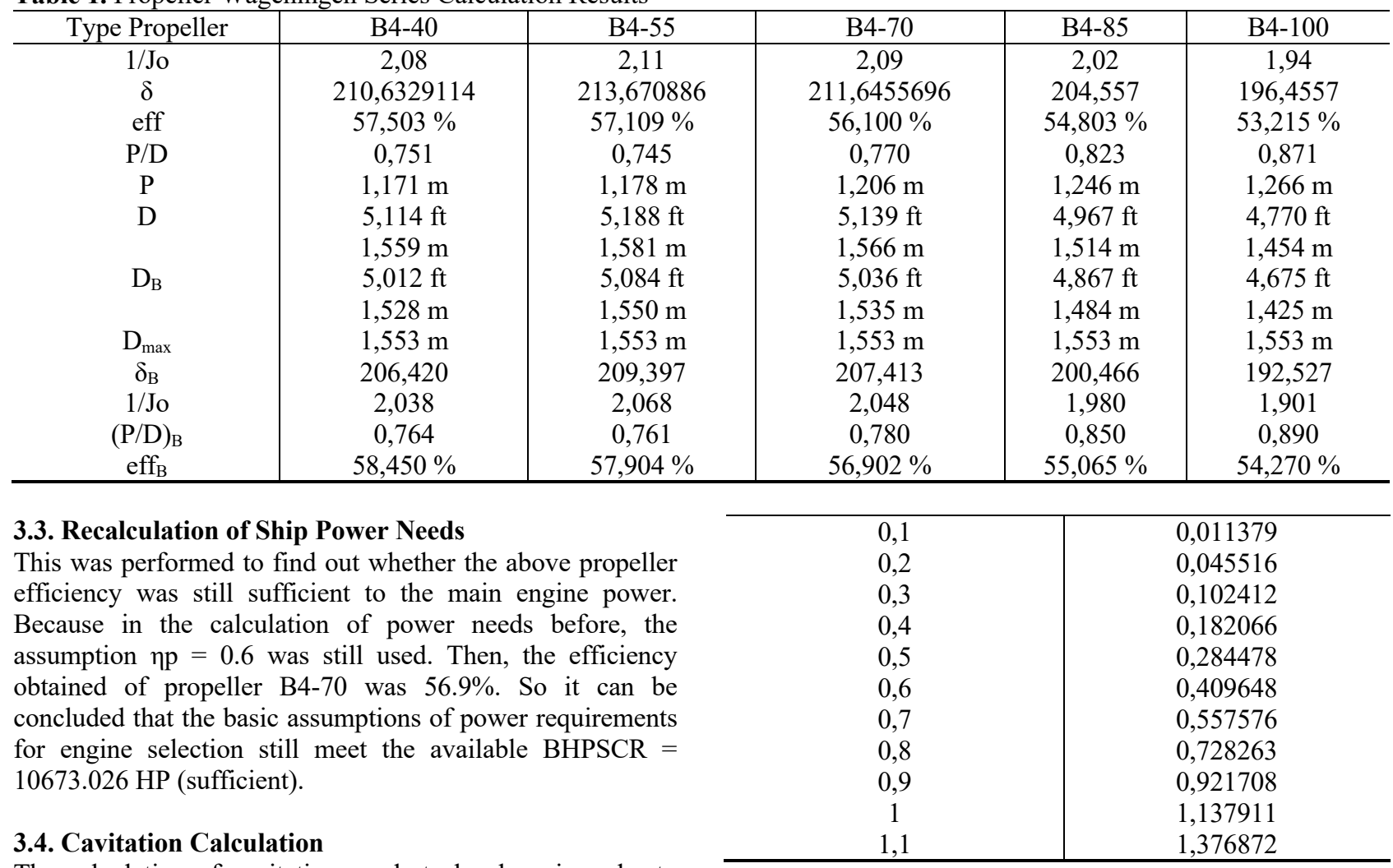

The calculation of cavitation needs to be done in order to ensure a free propeller of cavitation that causes fatal damage to the propeller. Determining the relationship between the ship's resistance and the speed of the vessel will be implemented in the form of the relationship between KT (Thrust coefficient) and J (Advance Coefficient).

Table 2. Relationship Between Kt and $\mathrm{J}$ in Trial Condition (Clean Hull)

\begin{tabular}{l|c} 
J & KT trial \\
\hline
\end{tabular}

The relationship between KT and $\mathrm{J}$ above was the relationship obtained in the trial condition (Clean Hull), to get the operation point of the propeller at the service condition then the sea margin price must also be considered. The price of sea margin would affect the size of the ship's resistance, therefore the relationship between $\mathrm{KT}$ and $\mathrm{J}$ would also change. The amount of sea margin suitable for cruise ships was $15 \%-30 \%$ for Asia-pacific [14]. 
Furthermore, based on the data that had been obtained, graph of the relationship between $\mathrm{KT}$ and $\mathrm{J}$ on the condition of trial (Clean Hull) can be made as presented below:

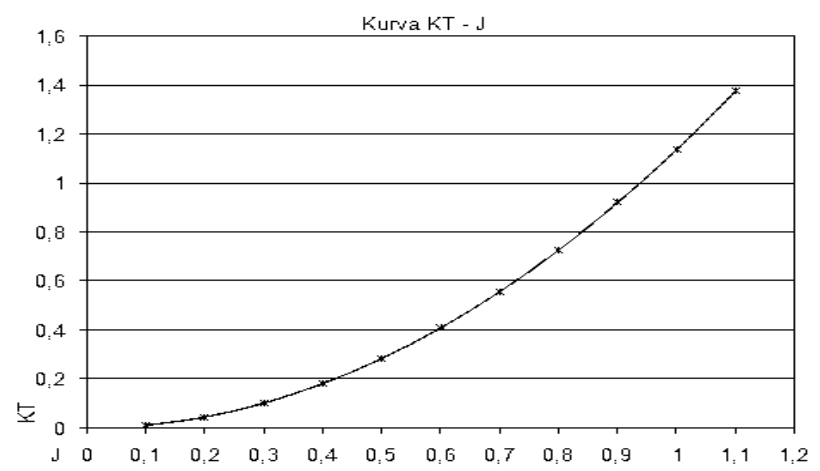

Fig. 5. Relationship between Kt and J on Trial Condition (Clean Hull)

\subsection{Propeller Characteristic}

In designing the characteristics of propeller type B series 470 Wageningen series for fix propeller was used.

Table 3. Graph open Water Propeller B4-70 Interpretation Results

\begin{tabular}{c|c|c|c}
\hline $\mathrm{P} / \mathrm{D}=0,78$ & & \\
\hline $\mathrm{J}$ & $\mathrm{KT}$ & $10 \mathrm{KQ}$ & Efisiensi \\
0,000 & 0,350 & 0,430 & 0,000 \\
0,100 & 0,320 & 0,400 & 0,130 \\
0,200 & 0,288 & 0,365 & 0,252 \\
0,300 & 0,250 & 0,328 & 0,368 \\
0,400 & 0,210 & 0,280 & 0,471 \\
0,500 & 0,169 & 0,231 & 0,568 \\
0,600 & 0,120 & 0,182 & 0,627 \\
0,700 & 0,070 & 0,131 & 0,621 \\
0,800 & 0,0250 & 0,078 & 0,432 \\
0,900 & 0,000 & 0,027 & 0,000 \\
1 & 0 & 0 & 0 \\
1,1 & 0 & 0 & 0 \\
\hline
\end{tabular}

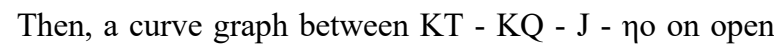
water test $\mathrm{B} 4-70$ in the table above was made and presented in the figure below:

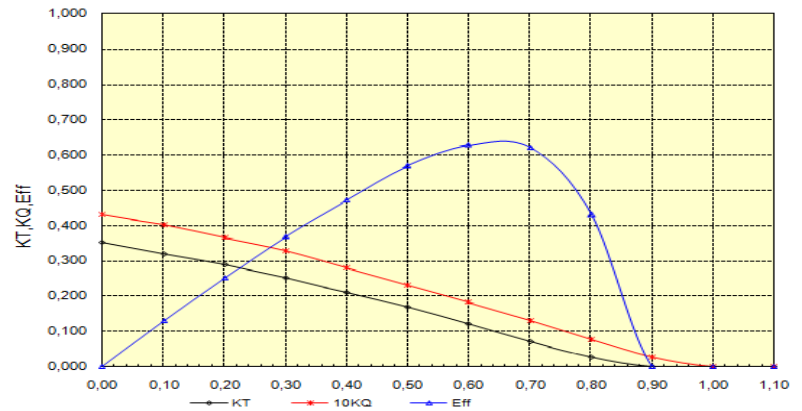

Fig. 6. $\mathrm{K}_{\mathrm{T}}-\mathrm{K}_{\mathrm{Q}}-\mathrm{J}-\mathrm{H}_{\mathrm{o}}$ Curve in Open Water Test B4-70

\subsection{Engine-Propeller Matching}

The graph of resistance KT-J characteristic with open water test curve B4-70 was presented as follows:

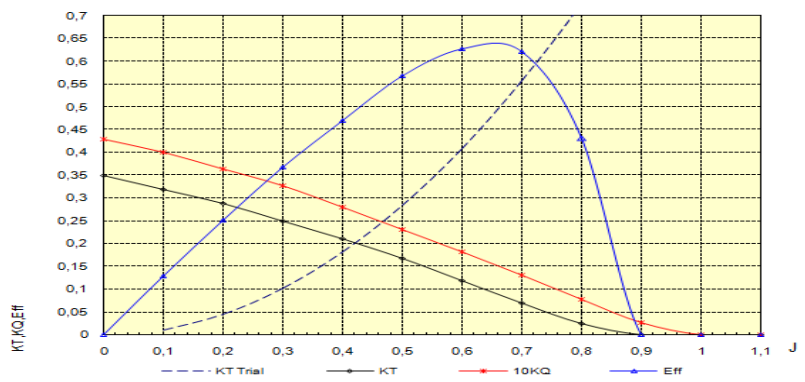

Fig. 7. $\mathrm{K}_{\mathrm{T}}-\mathrm{J}$ Curve with Curve in Open Water Test B4-70

\subsection{The Calculation of Delivered Power in Trial} Condition (Clean Hull).

Based on the table delivered power on the above trial conditions, it could be described in the form of diagrams below:

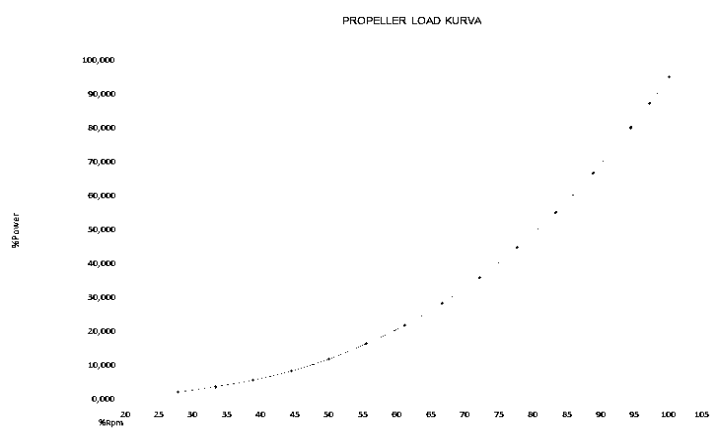

Fig. 8. Propeller B4.70 Load Curve

Table 4. Delivered Power in Trial Condition (Clean Hull)

\begin{tabular}{|c|c|c|c|c|c|c|c|}
\hline Rps & Rpm propeller & Rpm M/E & $\mathrm{Q}$ trial & Pd trial (HP) & $\mathrm{Pb}$ trial $(\mathrm{HP})$ & $\% \mathrm{Rpm}$ & $\%$ Trial Power \\
\hline 3,933 & 235,96 & 500 & 3377,168 & 104,2582 & 108,5570208 & 27,778 & 2,034 \\
\hline 4,719 & 283,15 & 600 & 4863,121 & 180,1581 & 187,5865319 & 33,333 & 3,515 \\
\hline 5,506 & 330,34 & 700 & 6619,248 & 286,0844 & 297,8804651 & 38,889 & 5,582 \\
\hline 6,292 & 377,54 & 800 & 8645,549 & 427,0414 & 444,6495572 & 44,444 & 8,332 \\
\hline 7,079 & 424,73 & 900 & 10942,023 & 608,0336 & 633,1045453 & 50 & 11,864 \\
\hline 7,865 & 471,92 & 1000 & 13508,670 & 834,0653 & 868,4561663 & 55,556 & 16,274 \\
\hline 8,652 & 519,11 & 1100 & 16345,491 & 1110,1409 & 1155,915157 & 61,11 & 21,660 \\
\hline 9,438 & 566,30 & 1200 & 19452,485 & 1441,2648 & 1500,692255 & 66,667 & 28,121 \\
\hline 10,225 & 613,50 & 1300 & 22829,653 & 1832,4415 & 1907,998197 & 72,222 & 35,754 \\
\hline 11,011 & 660,69 & 1400 & 26476,994 & 2288,6752 & 2383,04372 & 77,778 & 44,655 \\
\hline 11,798 & 707,88 & 1500 & 30394,508 & 2814,9704 & 2931,039561 & 83,333 & 54,924 \\
\hline 12,585 & 755,07 & 1600 & 34582,196 & 3416,3315 & 3557,196457 & 88,889 & 66,658 \\
\hline 13,371 & 802,27 & 1700 & 39040,057 & 4097,7628 & 4266,725145 & 94,444 & 79,953 \\
\hline 13,764 & 825,86 & 1750 & 41370,303 & 4470,0687 & 4654,382266 & 97,222 & 87,218 \\
\hline 14,158 & 849,46 & 1800 & 43768,092 & 4864,2688 & 5064,836362 & 100 & 94,909 \\
\hline
\end{tabular}

\section{Discussion}

Engine load characteristics obtained from the main engine data MTU 16V 595 TE 70L was described as follows: 
Table 5. Engine Load Characteristic Data

\begin{tabular}{c|c|c|c|c}
\hline Rpm ME & Power $\mathbf{( K w )}$ & Power $\mathbf{( H p )}$ & \% Power & \% Rpm \\
\hline 500 & 0 & 0 & 0 & 27,778 \\
500 & 400 & 543,8485 & 10,1910828 & 27,778 \\
600 & 566 & 769,5456 & 14,42038217 & 33,333 \\
700 & 760 & 1033,312 & 19,36305732 & 38,889 \\
800 & 950 & 1291,64 & 24,20382166 & 54,444 \\
900 & 1170 & 1590,757 & 29,8089172 & 55,556 \\
1000 & 1425 & 2311,356 & 36,30573248 & 61,111 \\
1100 & 1700 & 2678,454 & 43,31210191 & 66,667 \\
1200 & 1970 & 3127,129 & 50,1910828 & 72,222 \\
1300 & 2300 & 3555,409 & 58,59872611 & 77,778 \\
1400 & 2615 & 4024,479 & 66,62420382 & 83,333 \\
1500 & 2960 & 4561,529 & 75,41401274 & 88,889 \\
1600 & 3355 & 5084,983 & 85,47770701 & 94,444 \\
1700 & 3740 & 5336,513 & 95,2866242 & 97,222 \\
1750 & 3925 & 5336,513 & 100 & 100 \\
1800 & 3925 & 0 & 100 & 100 \\
1800 & 0 & & 0 & \\
\hline
\end{tabular}

Then, the data for propeller load characteristics of the MTU machine 16V 595 TE 70L was described as follows:

Table 6. Propeller Load Characteristic Data

\begin{tabular}{c|c|c|c|c|c}
\hline Rpm ME & Rpm propeller & Propeller Power $(\mathbf{K w})$ & Propeller Power (HP) & \% Power & \% Rpm \\
\hline 500 & 235,9604 & 95 & 129,164 & 2,420382 & 27,778 \\
600 & 283,1524 & 130 & 176,7508 & 3,312102 & 33,333 \\
700 & 330,3445 & 210 & 285,5204 & 5,350318 & 38,889 \\
800 & 377,5366 & 315 & 428,2807 & 8,025478 & 44,444 \\
900 & 424,7286 & 450 & 611,8295 & 11,46497 & 50 \\
1000 & 471,9207 & 625 & 849,7632 & 15,92357 & 55,556 \\
1100 & 519,1128 & 760 & 1033,312 & 19,36306 & 61,111 \\
1200 & 566,3049 & 1060 & 1441,198 & 27,00637 & 66,667 \\
1300 & 613,4969 & 1350 & 1835,489 & 34,3949 & 72,222 \\
1400 & 660,689 & 1700 & 2311,356 & 43,3121 & 77,778 \\
1500 & 707,8811 & 2090 & 2841,608 & 53,24841 & 83,333 \\
1600 & 755,0731 & 2533 & 3443,92 & 64,53503 & 88,889 \\
1700 & 802,2652 & 3050 & 4146,845 & 77,70701 & 94,444 \\
1750 & 825,8613 & 3300 & 4486,75 & 84,07643 & 97,222 \\
1800 & 849,4573 & 3610 & 4908,232 & 91,97452 & 100 \\
\hline
\end{tabular}

Based on the data about the main engine above, we could make the engine envelopecurve to be plotted with propeller load B4-70. This was done to determine whether the selected stapler and propeller had been matched or matched. Here is the curve of the basic machine data above:

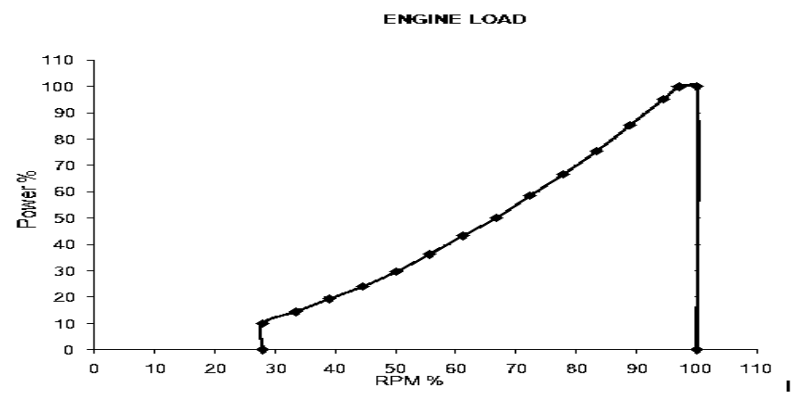

Fig. 9. Engine Load Characteristic Curve

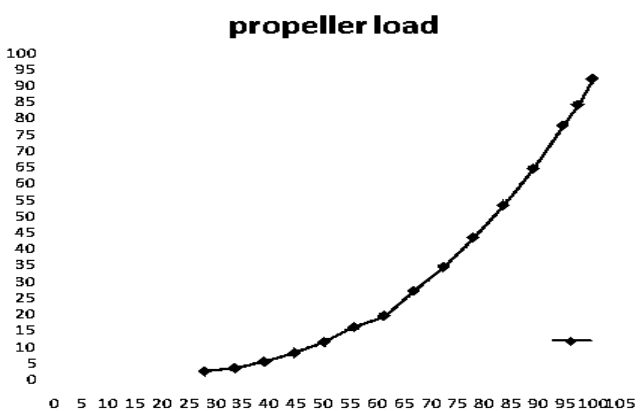

Fig. 10. Propeller Load Characteristic Curve

Furthermore, the engine and propeller load characteristics curve abovewass plotted with the result of propeller load calculation from the selected propeller that was propeller type B4.70. The plot was described as follows: 
Arica Dwi Susanto, I. Nengah Putra. A, Sentot Patria. W.S, Oyu Mulia. S and M. Agus Arif/

Journal of Engineering Science and Technology Review 12 (4) (2019) 202 - 208

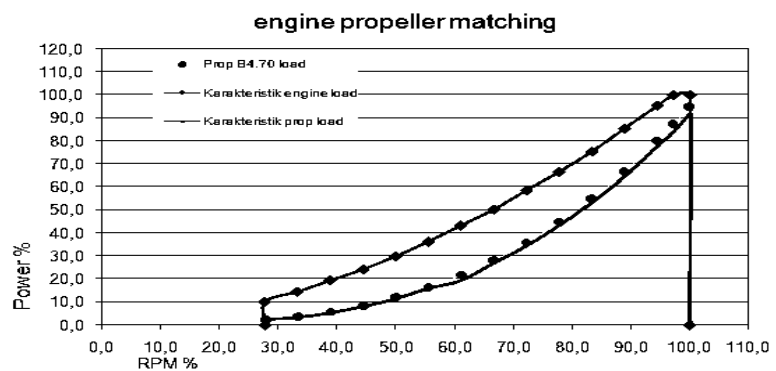

Fig. 11. Engine-Propeller Curve

The results of the engine-propeller matching curve readings could be expressed as follows:

Table 7. Interpretation Results of Engine Curve - Propeller Matching

\begin{tabular}{lccc}
\hline Analysis & $\begin{array}{c}\text { \% } \\
\text { Rpm }\end{array}$ & $\begin{array}{c}\text { Power } \\
(\mathbf{H p})\end{array}$ & $\begin{array}{c}\text { \% of } \\
\text { power }\end{array}$ \\
\hline Engine Load & 100 & 5336,513 & $100 \%$ \\
Propeller Load & $\begin{array}{c}\% \\
\text { 100 }\end{array}$ & 4908,232 & $91,975 \%$ \\
& $\%$ & &
\end{tabular}

\begin{tabular}{lccc} 
Propeller B4.70 & 100 & 5064,836 & $94,909 \%$ \\
Load & $\%$ & & \\
\hline
\end{tabular}

\section{Conclusion}

Based on the calculation results data above, the Propeller load of $5064.836 \mathrm{Hp}$ and the power percentage of $94.909 \%$ were obtained. When compared to the propeller load characteristics of the MTU 16V 595 TE 70L 4908.232 machine with the power percentage of $91.975 \%$, then wageningen series type B4.70propeller meets the propeller work area. The power margin above $90 \%$ in a clean hull condition indicated that it is very capable to keep the ship service conditions as expected at a maximum speed of 25 knots.

\section{Acknowledgements}

This research has been Supported by Indonesia Naval Technology College (STTAL).

This is an Open Access article distributed under the terms of the Creative Commons Attribution License

\section{References}

[1] A. D. Susanto.et.al., "Analysis of The Propulsion System Towards The Speed Reduction of Vessels Type PC-43," International Journal of Engineering Research and Application, pp. 8-15, 2017.

[2] K. Żelazny, "An Approximate Method For Calculation of Mean Statistical Value of Ship Service Speed On a Given Shipping Line , Useful In Preliminary Design Stage," Polish Maritime Research, pp. 28-35, 2015.

[3] H. H. Chun.et.al., "Experimental investigation on stern-boat deployment system and operability for Korean coast guard ship," International Journal Naval Architecture Ocean Engineering, pp. 488-503, 2013.

[4] J. K. a. A. Amin, "Performance of VLCC Ship with Podded Propulsion System and Rudder," International Society of Ocean, Mechanical and Aerospace Scientists and Engineers, pp. 1-7, 2014.

[5] E. Tupper, Introduction to Naval Architecture, Inggris: Great Britain, 1975.

[6] K. R. Tupper, Basic Ship Theory, Inggris: Great Britain, 2001.

[7] D. G. Watson, Practical Ship Design, Netherlands: Elsevier Science Ltd, 1998.

[8] S. R. Anthony F. Molland, Ship Resistance and Propulsion, United Stated of America: Practical Estimation of Ship Propulsive Power, 2011.

[9] V. Bertram, Practical Ship Hydrodynamic, Inggris: Great Britain, 2000.

[10] D. I. F. a. N. Samson, "Effect of Fluid Density On Ship Hull Resistance and Powering," International Journal of Engineering Research and General Science, pp. 615-630, 2015.

[11] A. M. D'arcalengelo, Ship Design and Contruction, Michigan: Professor of Naval Architecture and Marine Engineering University of Machigan, 1969.

[12] T. L. WPA Van Lamerren, Resistance Propulsion and Steering of Ship, Holland: Harleem Holland, 1984.

[13] N. S. a. S. Adumene, "Predictive Analysis of Bare-Hull Resistance of a 25,000 Dwt Tanker Vessel," International Journal of Engineering and Technology, pp. 194-198, 2015.

[14] S. A. Harvald, Resistance and Propulsion of Ships, New York: John Wiley and Sons, 1992.

[15] J. P. Andersen, Hydrodynamic of Ship Propeller, Cambridge: Elsevier, 1994

[16] H. S. a. V. Bertram, Ship Design for Efficiency and Economy, Great Britain: Butterworth-Heinemann, 1998.
[17] D. L. Bartee, "Design of Propulsion Systems for Hidh-Speed Craft," The Society of Naval Architects and Marine Engineers, pp. $1-17,1975$.

[18] K. Zelazny, "Amethod of Calculation of Ship Resistance on Calm Water Useful at Preliminary Stages of Ship Design," Scientific Journal Maritime University of Szuczecin, pp. 125-130, 2014.

[19] N. Degiuli.et.al., "Increase of Ship Fuel Consumption Due to the Added Resistance in Waves," Journal of Sustainable Development of Energy, Water and Environment Systems, pp. 1-14, 2017.

[20] M. I. Samuel, “An Inventigation Into The Resistance Components of Converting a Traditional Monohull Fishing Vessel Into Catamaran Form," International Journal of Technology, pp. 1-10, 2015.

[21] K. Atreyapurapu.et.al, "Simulation of a Free Surface Flow over a Container Vessel Using CFD," International Journal of Engineering Trends and Technology, pp. 334-339, 2014.

[22] K. Kleppesto, "Empirical Prediction of Resistance of Fishing Vessels," NTNU Trondheim Norwegion University of Science And Technology, pp. 1-87, 2015.

[23] A. Charchalis, "Designing Constraints in Evaluation of Ship Propulsion Power," Journal of KONES Powertrain and transport, pp. 1-6, 2013.

[24] J. K. Tabaczek, "Coefficients of Propeller-hull Interaction in Propulsion System of Inland Waterway Vessels with Stern Tunnels," International Journal on Marine Navigation and Safety of Sea Transportation, pp. 1-8, 2014.

[25] A. Kowalski, "Cost optimization of marine fuels consumption as important factor of control ship's sulfur and nitrogen oxides emissions," Scientific Journals, pp. 94-99, 2013.

[26] P. K. Premchand, "Numerical Investigation of the Influence of Water Depth on Ship Resistance," International Journal of Computer Applications , pp. 1-8, 2015.

[27] G. Kuiper, The Wageningen Propeller Series, Netherland: MARIN, 1992.

[28] E. V. Lewis, Principles of Naval Architecture Second Revision, New Jersey: The Society of Naval Architecs and Marine Engineers, 1988.

[29] J. Sladky, Marine Propulsion, New York: The Winter Annual Meeting of The American Society of Marine Engineers, 1976.

[30] D. Gerr, Propeller Handbook, J. E. a. D. Oppenheim, Penyunt., United Stated: International Marine, 2001.

[31] J. Herdzik, "Problems of propulsion systems and main engines choice for offshore support vessels," Scientific Journals Zeszyty Naukowe, vol. 2, no. 1733-8670, pp. 45-50, 2013. 
[32] R. L. Harrington, Marine Engineering, Revised, Subsequent penyunt., Revised, Penyunt., Jersey City, United States: The Society of Naval Architects and Marine Engineers, 1992.
[33] H. E. a. H. S. A. Guldhammer, Ship Resistance, Copenhagen: Akademisk Forlag, 1974.

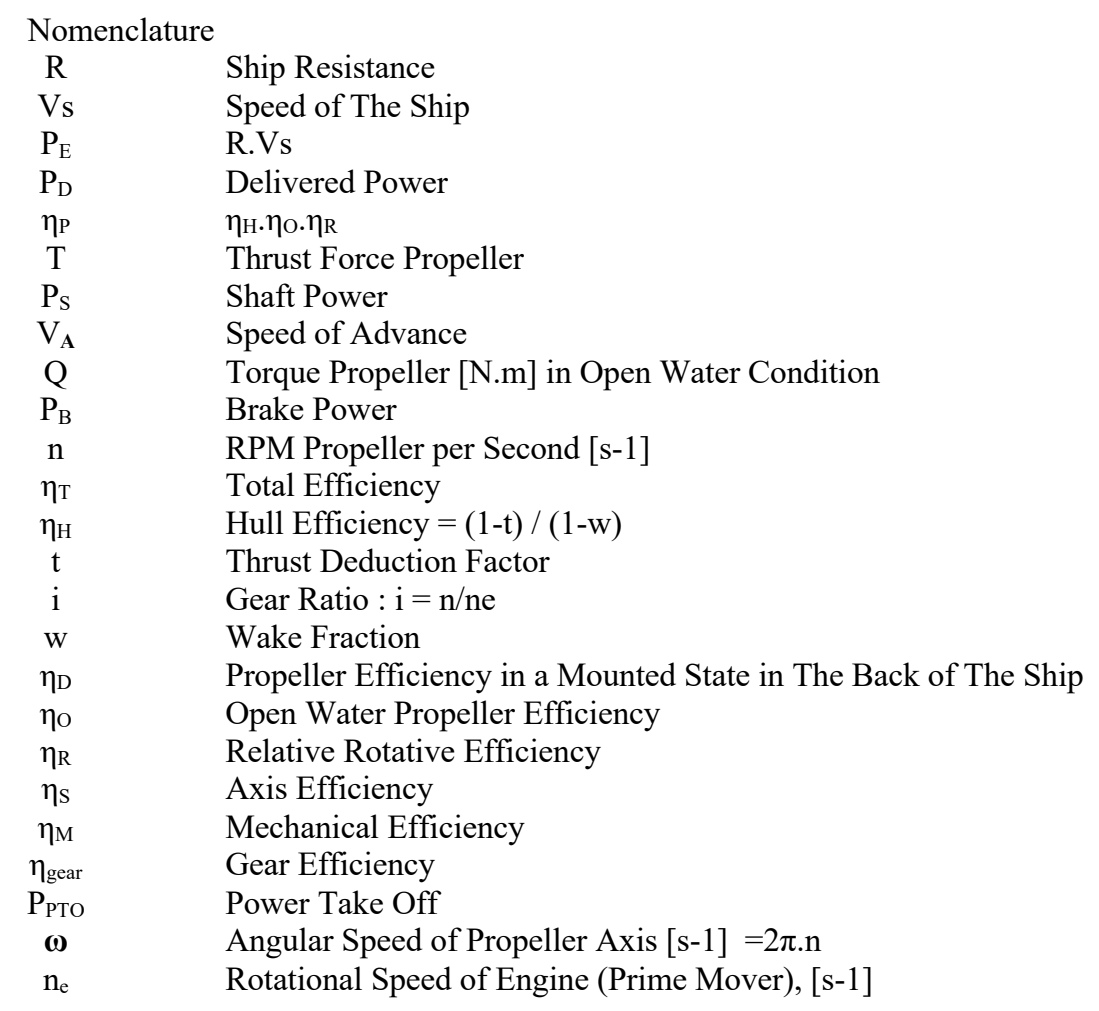

